\title{
Successful Outcome of Anterior Cruciate Ligament (ACL) Reconstruction by Hamstring Tendon for Anterior Cruciate Ligament Deficit Knee at a University Hospital: A Descriptive Cross-sectional Study
}

\author{
Rohit Shrestha, ${ }^{1}$ Sushant Kumar Khadka, ${ }^{1}$ Sangharsha Thapa ${ }^{2}$ Manasil Malla, ${ }^{2}$ Ashkal Basi, ${ }^{2}$ Prabha \\ Bhandari, ${ }^{2}$ Laxman Aryal, ${ }^{2}$ Binay Kandel, ${ }^{3}$ Umesh Adhikari ${ }^{3}$ \\ 'Department of Orthopedics, Dhulikhel Hospital, Dhulikhel, Nepal, ${ }^{2}$ Kathmandu University School of Medical Sciences, \\ Dhullikhel, Nepal, ${ }^{3}$ Department of Physiotherapy, Dhulikhel Hospital, Dhulikhel, Nepal.
}

\section{ABSTRACT}

Introduction: Anterior cruciate ligament is a commonly injured and reconstructed ligament in the knee. Unlike in urban areas where sports activities and road accidents are common mechanisms of injuries, the semi-urban and rural population has a different mode of injuries, needs, and expectations. This study explores the prevalence of successful outcome of anterior cruciate ligament reconstruction in by hamstring tendon for anterior cruciate ligament deficit knee at a university hospital.

Methods: A descriptive cross-sectional study was conducted at Dhulikhel Hospital, Kathmandu University Hospital from 2018 February to 2020 January among patients having anterior cruciate ligament injuries after ethical approval. Whole sampling technique was used. Functional outcome was assessed with Lysholm scale at the end of at least one year. Data was analysed using Statistical Package for Social Sciences version 11. Point estimate at 95\% Confidence Interval was calculated, with frequency and percentage.

Results: Out of 66 anterior cruciate ligament reconstruction, 35 (59\%) cases had successful outcomes. Excellent outcomes were seen in $9(15 \%)$ cases and $26(44 \%)$ had good outcomes. The mean Lysholm score was 84 .

Conclusions: Anterior cruciate ligament injuries were seen in heterogeneous populations during their activities of daily living or recreational sports activities. Anatomic anterior cruciate ligamentreconstruction with hamstring grafts provided good functional outcomes, especially among the young population. Our findings are similar to current studies on anterior cruciate ligament-reconstruction.

Keywords: anterior cruciate ligament; arthroscopy; knee.

\section{INTRODUCTION}

The Anterior cruciate ligament (ACL) provides anteroposterior and rotational stability at the knee joint and hence it is crucial for various activities of daily living (ADL) like running, climbing stairs, and turning around the corners. ${ }^{1-5} \mathrm{ACL}$ is one of the most commonly injured and reconstructed ligaments in the knee. ${ }^{6,7}$

The available literature on ACL injuries primarily focuses on young active individuals involved in sports activities. The populations in a semi-urban and rural setup, however, have different modes of injuries, needs, and expectations. ${ }^{8}$ Their ADLs include going uphill or downhill carrying a load on their back which requires knee strength and coordination. The evidence on the outcome of $A C L$ reconstruction on this population is not well documented and yet to be explored.

Correspondence: Dr. Rohit Shrestha, Department of Orthopedics, Dhulikhel Hospital, Dhulikhel, Nepal. Email: rohitshrestha@kusms.edu.com.np, Phone: +9779801002272. 
Shrestha et al. Successful Outcome of Anterior Cruciate Ligament (ACL) Reconstruction by Hamstring Tendon for Anterior Cruciate...

Hence, this study explores the prevalence of successful outcome of anterior cruciate ligament reconstruction in by hamstring tendon for anterior cruciate ligament deficit knee at a university hospital.

\section{METHODS}

With ethical approval from Institutional Review Committee KUSMS (approval no 006/19), a descriptive cross-sectional study was carried out at Dhulikhel Hospital, Kathmandu University Hospital from 2018 February until 2020 January among skeletally matured patients (age 16 to 60 years range, both males and females). They were the people presented with features suggestive of knee instability and supported by Magnetic Resonating Imaging findings of $A C L$ deficiency and received arthroscopic single-bundle $A C L$ reconstruction ( $A C L-R$ ) with ipsilateral hamstring autograft. The exclusion criteria were cases with multiligamentous injuries, acute $A C L$ repairs, $A C L$ injuries associated with fractures, and $A C L$ reconstructed with grafts other than hamstrings. Written informed consent was taken from all the participants. Whole sampling technique was used.

Sample size was calculated using the formula

$$
\begin{aligned}
\mathrm{n} & =\mathrm{Z}^{2} \times \mathrm{p} \times \mathrm{q} / \mathrm{e}^{2} \\
& =(1.64)^{2} \times 0.76 \times(1-0.76) /(0.09)^{2} \\
& =60.56
\end{aligned}
$$

Where,

$\mathrm{n}=$ minimum required sample size for infinite population $Z=1.64$ at $90 \%$ Confidence Interval $(\mathrm{Cl})$

$\mathrm{p}=$ prevalence based on a similar study done in the past, $76 \%^{9}$

$q=1-p$

$\mathrm{e}=$ margin of error, $9 \%$

Standard trans portal anatomic single bundle ACL-R was done with graft anchored at the femoral side with fixed loop Endobutton (Smith and Nephew) and at the tibial side with bio-absorbable Interference screw (Polylevolactic acid - Smith and Nephew) of appropriate dimension. A negative pivot shift test under anesthesia after ACL-R was taken as an immediate indicator for adequate stability.

Postoperative protocols included standard care for wound management along with active rehabilitation that included isometric knee exercises which were started from post-operative day one, supervised a range of motion as tolerated, and was targeted to achieve full active extension and 90 degrees of knee flexion by the end of the first week. Patients were discharged after they were able to weight bear and ambulate with crutches or walkers as required and climb stairs under supervision. Hinged knee braces were prescribed only in cases where patients were not able to cope with the early postoperative rehabilitation protocol. Crutches were weaned off progressively from the fourth to eighth week depending on the patients' tolerance and gait. Physiotherapy was continued to strengthen the limb and improve power, proprioception, and range of motion.

The functional outcome was measured with the Lysholm scale, which is a 100 point scoring system consisting of eight sections, namely: limp, using walking aids, knee locking, knee giving way, pain, swelling, climbing stairs, and squatting. Single hop test (hop index) for distance, which represents the ability of a person to jump a certain distance with the operated limb as compared to his / her contralateral limb expressed in percentage, was used to assess strength and coordination. Data was analysed using Statistical Package for Social Sciences (SPSS) version 11. Point estimate at $95 \%$ Confidence Interval was calculated, with frequency and percentage.

\section{RESULTS}

Out of 66 anterior cruciate ligament reconstruction, $35(59 \%)$ cases had successful outcomes. Excellent outcomes were seen in $9(15 \%)$ cases and 26 (44\%) had good outcomes. The mean Lysholm score was 84 .

The male to female ratio was $1.2: 1$. Both right and left knees were equally involved. Most of the patients were farmers and household workers followed by students. The majority of the patients were from Kavrepalanchowk district in the mid-hilly region of the country. Road traffic accidents and sports were the common mechanisms of injury among males, whereas, twisted knee injuries while performing activities of daily living (ADL) were common among the ladies (Table 1). The majority of the people receiving $A C L-R$ were young and middle-aged with a mean age of 30.4 years and a range of 17 to 51 years. Twenty to thirty years was the common age group among males suffering $A C L$ injuries while 30 to 40 years was the common age group in females. Thirtythree $(50 \%)$ patients had medial meniscus injury and 15 patients had lateral meniscus injury where seven patients were common in both the menisci injury. All meniscus injuries were managed either with a repair or partial meniscectomy as deemed appropriate.

\begin{tabular}{|ll|}
\hline $\begin{array}{l}\text { Table 1. Demographic and Epidemiologic Parameters } \\
\text { (n=66). }\end{array}$ \\
\hline Gender & $\mathbf{n}(\%)$ \\
Male & $36(54.5)$ \\
Female & $30(45.5)$ \\
\hline Side & $34(51.5)$ \\
Right & $32(48.5)$ \\
Left & \\
Profession & $21(31.8)$ \\
Students
\end{tabular}


Shrestha et al. Successful Outcome of Anterior Cruciate Ligament (ACL) Reconstruction by Hamstring Tendon for Anterior Cruciate...

\begin{tabular}{|ll|} 
Farmers \& Household Work & $22(33.3)$ \\
Office worker & $13(19.7)$ \\
Others (shops..) & $9(13.6)$ \\
Address (Districts) & \\
Mid Hilly Regions & $42(63)$ \\
Kavrepalanchowk & $25(38)$ \\
$\begin{array}{l}\text { Sindhupalchowk } \\
\text { Others (Bhojpur, Ramechhap, Syanja, } \\
\text { Kaski, Pyuthan, and Tanahu) }\end{array}$ & $5(8)$ \\
$\begin{array}{l}\text { Terai \& Madhesh } \\
\text { Kathmandu Valley }\end{array}$ & $9(14)$ \\
$\begin{array}{l}\text { Injury Mechanism } \\
\text { Fall-related }\end{array}$ & $15(23)$ \\
$\begin{array}{l}\text { Road traffic accidents } \\
\text { Sports activities }\end{array}$ & $6(9)$ \\
$\begin{array}{l}\text { Twisted injury while ADL (like } \\
\text { downhill walking with load at back) }\end{array}$ & $14(21.2)$ \\
\hline
\end{tabular}

The majority 25 (38\%) of the patients were operated on within three months of their ACL injury. On average, patients needed five days of inpatient care for wound management and physiotherapy training before they could be discharged. One of the patients needed anterolateral ligament ( $A L L$ ) reconstruction as he had a positive pivot shift test immediately after ACL-R. This patient was not included in the outcome analysis (Table 2).

\begin{tabular}{|ll|}
\hline \multicolumn{2}{|l|}{ Table 2. Details regarding Operative parameters. } \\
\hline Injury - Surgery Interval & $\mathbf{n}(\%)$ \\
within three months & $25(38)$ \\
three to six months & $22(33)$ \\
six months above & $19(29)$ \\
& 5 days \\
Median hospital stay & $8.0 \mathrm{~mm}$ \\
The median diameter of the final & \\
Hamstring graft & $84 \mathrm{~mm}$ \\
Mean length of the graft & $36 \mathrm{~mm}$ \\
Mean length of Femoral tunnel & \\
Length of graft intraarticular & \\
At least 25mm & $54(81.8)$ \\
More than 25mm & $12(18.2)$ \\
Graft Fold & $4(6)$ \\
Triplicated & $10(15.3)$ \\
Quadrupled & $46(69.7)$ [Median] \\
Pentapled & $6(9)$ \\
Hexapled &
\end{tabular}

There were 59 (89.4\%) patients available for final follow-up evaluation with a mean of 21 months (3312 months) after the ACL-R. The follow-up visits were significantly affected by the lockdown amid the COVID 19 crisis at the terminal part of the study. However, among the available candidates, the mean Lysholm score was 84 , and a majority 26 (44\%) of the patients were in a good category. Most of the patients had developed an equivalent range of knee movement as compared to the contralateral healthy side along with a negative pivot shift test at the follow-up.

Three patients had grade I positive pivot shift test and were managed conservatively. The mean hop index in the current study was $78 \%$, which shows that patients with $A C L$ reconstructed knees can hop on average of about $78 \%$ distance as compared to the contralateral (normal) side. The timing of ACL-R whether done within three months or three to six months or after six months did not show any difference in the functional outcome (Table 3).

\begin{tabular}{|c|c|c|}
\hline $\begin{array}{l}\text { Distribution of Lysholm } \\
\text { scores }\end{array}$ & n (\%) & \\
\hline Excellent (>90 score) & $9(15)$ & Success Rate \\
\hline Good (90 to 84$)$ & $26(44)$ & $\begin{array}{l}\text { (Excellent \& } \\
\text { Good) } \\
35(59 \%)\end{array}$ \\
\hline Fair (83 to 65$)$ & $21(36)$ & \\
\hline Poor $(=<64)$ & $3(4.5)$ & \\
\hline \multicolumn{3}{|l|}{$\begin{array}{l}\text { Range of motion of } \\
\text { knees }\end{array}$} \\
\hline $\begin{array}{l}\text { Same as that of the } \\
\text { contralateral knees }\end{array}$ & $52(88)$ & \\
\hline Extension lag & $3(5)$ & \\
\hline Flexion reduced & $4(6.8)$ & \\
\hline $\begin{array}{l}\text { Stability (post-op pivot } \\
\text { shift test) }\end{array}$ & $3(5)$ & All Grade 1 \\
\hline \multirow[t]{2}{*}{$\begin{array}{l}\text { Single Hop test for } \\
\text { Distance } \\
\text { (HOP INDEX)- Mean } \\
\text { For ACL reconstructed } \\
\text { Side X100 \% } \\
\text { For the contralateral } \\
\text { (Normal) side }\end{array}$} & $78 \%$ & \\
\hline & & Lysholm Score \\
\hline Injury to ACL-R Duration & n (\%) & Mean \pm SD \\
\hline within three months & $\begin{array}{l}21 \\
(35.59)\end{array}$ & $81.4 \pm 9.5$ \\
\hline three to six months & $\begin{array}{l}21 \\
(35.59)\end{array}$ & $83.6 \pm 8.7$ \\
\hline after six months & $\begin{array}{l}17 \\
(28.81)\end{array}$ & $84 \pm 7.6$ \\
\hline
\end{tabular}

Subgroup analysis revealed that outcome was significantly associated with occupation and age group of study population while there was no association among the gender and geographic distribution (Table $4)$. 
Shrestha et al. Successful Outcome of Anterior Cruciate Ligament (ACL) Reconstruction by Hamstring Tendon for Anterior Cruciate...

\begin{tabular}{|c|c|c|}
\hline & $\begin{array}{l}\text { Excellent \& } \\
\text { Good n (\%) }\end{array}$ & $\begin{array}{l}\text { Fair \& Poor } \\
\text { n (\%) }\end{array}$ \\
\hline \multicolumn{3}{|l|}{ Occupation } \\
\hline Students & $17(28.81)$ & $3(5.08)$ \\
\hline Office worker & $8(13.55)$ & $4(6.77)$ \\
\hline Others (Shop) & $5(8.47)$ & $4(6.77)$ \\
\hline Farmer and Housework & $5(8.47)$ & $13(22.03)$ \\
\hline \multicolumn{3}{|l|}{ Age (years) } \\
\hline$\leq 30$ & $25(42.37)$ & 8 (13.55) \\
\hline$>30$ & $10(16.94)$ & $16(27.11)$ \\
\hline \multicolumn{3}{|l|}{ Gender } \\
\hline Male & $19(32.20)$ & $14(23.72)$ \\
\hline Female & $16(27.11)$ & $10(16.94)$ \\
\hline \multicolumn{3}{|l|}{ Geographic Distribution } \\
\hline Hilly Districts & $21(35.59)$ & $18(13.50)$ \\
\hline Urban and Flat area & $14(23.72)$ & $6(10.16)$ \\
\hline
\end{tabular}

Per operative complications were noted in two cases. In one, there was a lateral wall blow out and this case was managed with an interference screw. In the other case, there was posterior and lateral wall blow out and this was managed with a femoral post. In five cases, tibial posts were used in addition to tibial interference screws for better graft security. All the cases were included in the study as this study did not differentiate on the type of graft fixation. No major intraarticular infection was noted during the study period. However, two cases presented with serosanguinous discharge at the tibial graft fixation site approximately one year later that needed local debridement and removal of fragments of interference screws. Three cases had grade I pivot shift, three had extension lag and four had flexion deficit at follow up and they were satisfied with conservative treatment with physiotherapy as they were the low demand patients.

\section{DISCUSSION}

The current study was carried out in a semi-urban to a rural setting in the mid-hilly region of the country, which correspondingly indicates the geographic terrain and the lifestyle of the people in their activities of daily living. The majority of the study population were involved in farming and almost half of the study population had their injury while performing household activities like walking up or downhill carrying a load at the back which is a typical rural lifestyle in the Nepali context. Sherchan B, et al. conducted a retrospective study in one of the tertiary care hospitals in Kathmandu which showed road traffic accidents as the most common mode of injury whereas Karn N, et al. found fall injury as the most common mode. ${ }^{9,10}$ These differences seen among Nepali articles might be attributed to the differences in the population composition and the study settings. Road traffic accidents, injuries related to falls, and sports are predominant in urban settings which represented their study population. The current study showed no differences in gender distribution whereas the majority of articles have shown ACL injuries and subsequently ACL-R were more common in males. This could be explained by the population demography of the mid-hilly rural population that included a relatively larger female population. ${ }^{9-12}$

The time interval from injury to $A C L-R$ in the current study was found to be similar to other studies when the cohort was arbitrarily divided into three groups. In a retrospective study done by Razi, et al. in Tehran, they found that $37 \%$ of patients were operated on within three months. ${ }^{13}$ However, a British study by Church S, et al. had $56 \%$ of patients operated within three months. ${ }^{14}$ The reason why the timing of ACL-R is interesting to consider is that functional outcome, chances of complications, and most importantly chances of meniscal injuries are related to the timing of surgery. There were significant increases in associated medial meniscus injury with a delay of ACL-R beyond three months in studies as shown by Sajjadi MM, et al. Church S, et al. and Fithian DC, et al. in their studies. ${ }^{14-17}$ Grossly, the current study agreed with the findings obtained in other available studies that medial meniscus was most often associated with an ACL injury. ${ }^{9,13-15}$ The current study showed, however, similar functional outcomes among the groups who were operated on in different periods. This inference could be more robust if the study could have larger populations in each subcategory to compare the outcomes.

Several pieces of literature have extensively studied the intraoperative parameters. Few studies had explored the femoral tunnel length and its application in ACL-R. ${ }^{16-19}$ Miller LC, et al. had studied the intra-articular graft length in cadaveric knees who had received ACL-R before. ${ }^{20}$ Though these parameters depend on many other technical considerations, in a standard practice they remain similar for a given population and the knowledge of standard values may help in the planning of the surgery. Given the paucity of information in the local context, the present study adds on knowledge of the intraoperative parameters like femoral tunnel length, intra articular graft length, the graft fold, and diameters obtained by hamstring graft in the average Nepali population, and that is also supported by the previous study. ${ }^{9}$ However, in absence of extensive studies, it would be premature to generalize yet.

The average Lysholm score of the study cohort was good. Excellent and good constituted about $60 \%$ of the study population while good and fair were seen in $80 \%$. Subgroup analysis revealed excellent and good 
Shrestha et al. Successful Outcome of Anterior Cruciate Ligament (ACL) Reconstruction by Hamstring Tendon for Anterior Cruciate...

category had more students and were of the younger population while people of age more than 30 years and occupation as farmer and household worker were more in the fair and poor category. This was just a crude observation and lacked enough evidence to derive a firm inference, however, differences in outcome may be attributed to multiple parameters like availability of rehabilitation supervision, early back to household activities, noncompliant with follow-ups, physical demand, and early or late weaning from the assistive device just to name a few of them. Interestingly the functional outcome was similar between the gender distribution and also the geographical location of the patient population. It could be argued that younger people and students have a better understanding of capacity, motivation, and access to proper post-op rehabilitation programs than their counterparts. ${ }^{21}$ Further research/studies would be appropriate to explore how the outcome results could be improved. The role of good physiotherapy and post-op rehabilitation cannot be underestimated.

The current study recognized certain limitations. The first was the use of the Lysholm score to measure the patient's reported functional outcome, which is yet to be translated and validated in local language and context for better credibility. The other was the need for larger samples and multi-center trials for firm inferences on cause and effect relationships. And finally, the current study did not segregate the associated meniscal injuries depending upon whether ACLR was done early or late, which would be a prospect for further study in the future.

\section{CONCLUSIONS}

ACL injuries were seen in heterogeneous populations during their activities of daily living or recreational sports activities. Anatomic ACL-R with hamstring grafts provided good functional outcomes, especially among the young and active population. Our findings are similar to current studies. The geographic location of residence of the study population and the timing of ACL-R did not affect their functional outcome.

\section{ACKNOWLEDGMENTS}

The authors would like to thank Dr. Bibek Basukala, Dr. Rajiv Sharma, Dr. Jagadish Thapa, for evaluating and managing cases. Dr. Sabik Rak Kayastha and Dr. Pooja Shrestha for assisting with statistical analysis and reviewing the manuscript.

\section{Conflict of Interest: None.}

\section{REFERENCES}

1. Mohtadi NG, Chan DS, Dainty KN, Whelan DB. Patellar tendon versus hamstring tendon autograft for anterior cruciate ligament rupture in adults. Cochrane Database Syst Rev. 2011 Sep 7;2011(9):CD005960. [PubMed | Full Text | $\underline{\mathrm{DOI}}$

2. Seitz H, Schlenz I, Muller E, Vécsei V. Anterior instability of the knee despite an intensive rehabilitation program. Clin Orthop Relat Res. 1996 Jul;(328):159-64. [라Med | Full Text | DOI]

3. Meuffels DE, Reijman M, Scholten RJ, Verhaar JA. Computer assisted surgery for knee ligament reconstruction. Cochrane Database Syst Rev. 2011 Jun 15;(6):CD007601. [ $\underline{\text { PubMed | }}$ $\underline{\text { Full Text }}$ | DOI]

4. Maletius W, Messner K. Eighteen- to twenty-four-year follow-up after complete rupture of the anterior cruciate ligament. Am J Sports Med. 1999 Nov-Dec;27(6):711-7. [PubMed $|\underline{\text { Full Text }}| \underline{\text { DOI] }}$

5. Heijne A, Werner S. A 2-year follow-up of rehabilitation after ACL reconstruction using patellar tendon or hamstring tendon grafts: a prospective randomised outcome study. Knee Surg Sports Traumatol Arthrosc. 2010 Jun;18(6):805-13. [PubMed | Full Text $\mid \underline{\text { DOI] }}$

6. Mall NA, Chalmers PN, Moric M, Tanaka MJ, Cole BJ, Bach $\mathrm{BR} \mathrm{Jr}$, et al. Incidence and trends of anterior cruciate ligament reconstruction in the United States. Am J Sports Med. 2014 Oct;42(10):2363-70. [라미 | Full Text | DOI]
7. Friel NA, Chu CR. The role of ACL injury in the development of posttraumatic knee osteoarthritis. Clin Sports Med. 2013 Jan;32(1):1-12. [PubMed | Full Text | DOI]

8. Griffin LY, Agel J, Albohm MJ, Arendt EA, Dick RW, Garrett WE, et al. Noncontact anterior cruciate ligament injuries: risk factors and prevention strategies. J Am Acad Orthop Surg. 2000 May-Jun;8(3):141-50. [라Med | Full Text | DOI]

9. Sherchan B, Rai S, Tamang N, Dhungana S, Sharma LK, Marasini RP, Singh JL, Khanal K. Outcomes of single bundle arthroscopic anterior cruciate ligament reconstruction in a limited resource setting. JISAKOS. 2021 Jul;6(4):187-92. [PubMed $|\underline{\text { Full Text }}| \underline{\text { DOI] }}$

10. Karn NK, Jha RK, Ranjan N. Anterior Cruciate Ligament Reconstruction using Bone Patellar Tendon Bone autograft in ACL deficient Knee. JCMS Nepal. 2015;11(3):12-5. [Full $\underline{\text { Text }}$ | DOI]

11. Kochhal N, Thakur R, Gawande V. Incidence of anterior cruciate ligament injury in a rural tertiary care hospital. J Family Med Prim Care. 2019 Dec 10;8(12):4032-5. [PubMed | Full Text | DOI]

12. Thapa SS, Lamichhane AP, Mahara DP. Accuracy of Lelli test for anterior cruciate ligament tear. J Inst Med. 2015;37(2):91-4. [Full Text]

13. Razi M, Salehi S, Dadgostar H, Cherati AS, Moghaddam $\mathrm{AB}$, Tabatabaiand SM, et al. Timing of Anterior Cruciate Ligament Reconstruction and Incidence of Meniscal and Chondral Injury within the Knee. Int J Prev Med. 2013 


\section{Apr;4(Suppl 1):S98-103. [PubMed | Full Text]}

14. Church S, Keating JF. Reconstruction of the anterior cruciate ligament: timing of surgery and the incidence of meniscal tears and degenerative change. J Bone Joint Surg Br. 2005 Dec;87(12):1639-42. [PubMed | Full Text | DOI]

15. Fithian DC, Paxton LW, Goltz DH. Fate of the anterior cruciate ligament-injured knee. Orthop Clin North Am. 2002 Oct;33(4):621-36. [PubMed | Full Text | DOI]

16. Celiktas M, Kose O, Sarpel Y, Gulsen M. Can we use intraoperative femoral tunnel length measurement as a clue for proper femoral tunnel placement on coronal plane during ACL reconstruction? Arch Orthop Trauma Surg. 2015 Apr;135(4):523-8. [uㅏMed | Full Text | DOI]

17. Sajjadi MM, Okhovatpour MA, Ebrahimpour A, Zandi R, Kafi-Abadi MJ, Sadighi M. Anterior cruciate ligament reconstruction surgery timing with respect to meniscal-chondral damage. Arch Trauma Res. 2018;7(3):87-91. [Full Text]

18. Lubowitz JH, Konicek J. Anterior cruciate ligament femoral tunnel length: cadaveric analysis comparing anteromedial portal versus outside-in technique. Arthroscopy. 2010 Oct;26(10):1357-62. [

19. Iriuchishima $\mathrm{T}$, Goto $\mathrm{B}$, Okano $\mathrm{T}$, Ryu $\mathrm{K}, \mathrm{Fu} \mathrm{FH}$. Femoral tunnel length in anatomical single-bundle ACL reconstruction is correlated with height, weight, and knee bony morphology. Knee Surg Sports Traumatol Arthrosc. 2019 Jan;27(1):93-9. [PubMed | Full Text | DOI]

20. Miller MD, Olszewski AD. Cruciate ligament graft intra-articular distances. Arthroscopy. 1997 Jun;13(3):291-5. [PubMed | Full Text | DOI]

21. Karthik MN, Satishkumar C. Accelerated rehabilitation is vital post anterior cruciate ligament reconstruction. Int J Orthop. 2020;6(1):1140-4. [Full Text | DOI] 